\title{
Editorial
}

\section{Qual a finalidade de uma publicação científica?}

\author{
Rodolfo Augusto Matteo Ambiel \\ Ana Paula Porto Noronba \\ Lucas de Francisco Carvalho \\ Universidade São Francisco - Campinas, SP, Brasil
}

Preparar um novo editorial é uma tarefa acompanhada de muitos significados. Representa o fim de um processo editorial complexo e longo, que se inicia aproximadamente doze meses antes da sua divulgação no Scielo. Também pode significar o início das tratativas de um novo número. Além disso, o que se pretende destacar, implica ampla análise do que se construiu enquanto ciência psicológica.

A Psico-USF é uma publicação do Programa de Pós-graduação Stricto Sensu em Psicologia da Universidade São Francisco, que recebeu na última avaliação quadrienal da CAPES a nota 7, reafirmando sua excelência e seu compromisso social e científico com a área de conhecimento. Assim, a revista é parte de suas atribuições e a avaliação se tornou uma prática constante.

Neste editorial gostaríamos de problematizar: qual a função da publicação científica? Seguramente ela não deve existir para atender ao chamado 'produtivismo' (Guedes, 2011). A publicação é a finalização da pesquisa, é a contribuição social do autor, e é por meio dela que poderá ser contada a história daquele estudo e seus respectivos achados (Trzesniak, 2009). A escolha do periódico faz parte do processo de 'contar a história', pois se elege o público com o qual se deseja compartilhar e para o qual os dados serão úteis (Barata, 2015).

Com base nessa premissa, a Psico-USF apresenta aos seus leitores o segundo número de 2018. Nesse volume 23, número 2, são oferecidos 14 artigos inéditos referentes às diversas temáticas da Psicologia. Agradecemos aos autores e pareceristas pelas contribuições e esperamos que nossos leitores desfrutem desses trabalhos e possam adquirir novos conhecimentos.

A presente edição é iniciada com o trabalho The Construction of the Psycho-sociological Knowledge on Diabetes Mellitus, o qual Fabrycianne Gonçalves Costa e Maria da Penha de Lima Coutinho são autoras. O objetivo das autoras foi analisar as Representações Sociais que pessoas com diabetes elaboram sobre o diabetes mellitus e seu tratamento.

O foco do trabalho de Helder Kamei, Maria Cristina Ferreira, Felipe Valentini, Mario Peres, Patrícia Tobo e Bruno Figueiredo Damásio foi apresentar evidências de validade para a versão brasileira reduzida do Questionário de Capital Psicológico. O título do artigo é Psychological Capital Questionnaire - Short Version (pcq-12): Evidence of Validity of the Brazilian Version.

Thaís Ramos de Carvalho, Elizabeth Joan Barham, Carolina Duarte de Souza, Elisangela Böing, Maria Aparecida Crepaldi e Mauro Luís Vieira verificaram a adequação de uma adaptação transcultural do Coparenting Relationship Scale no contexto brasileiro. Esse artigo é intitulado Cross-cultural Adaptation of an Instrument to Assess Coparenting: Coparenting Relationship Scale.

O objetivo do artigo intitulado Marital Conflict Management of Married Men and Women foi verificar o uso de estratégias construtivas e destrutivas de resolução de conflitos entre homens e mulheres casados e identificar associações dessas estratégias com variáveis sociodemográficas e características do relacionamento. A autoria é de Marina Zanella Delatorre e Adriana Wagner.

Predictors of Marital Physical Violence: Personal and Relational Characteristics é um estudo de Karla Rafaela Haack, Juliana Pressi e Denise Falcke. As autoras investigaram o poder preditivo de experiências na família de origem, amor, ajustamento conjugal, esquemas iniciais desadaptativos e clima familiar para a ocorrência de violência física conjugal.

O objetivo das autoras Natália Zancan e Luísa Fernanda Habigzang foi avaliar as relações entre níveis de regulação emocional, ansiedade e depressão em mulheres com experiência de violência conjugal. $\mathrm{O}$ artigo foi intitulado Regulação Emocional, Sintomas de Ansiedade e Depressão em Mulheres com Histórico de Violência Conjugal.

O trabalho intitulado Paternidade em Diferentes Configuracõoes Familiares e o Desenvolvimento Emocional da Filha é de autoria de Andressa Pin Scaglia, Fernanda Kimie Tavares Mishima-Gomes e Valéria Barbieri. O objetivo das autoras foi compreender como pais inseridos em diferentes configurações familiars experimentam a função paterna, associando suas vivências ao desenvolvimento do self de suas filhas.

Yasmin Bruna Patrycia Waligura de Oliveira, Ana Karoline Gomes Gurtat e Aline Henriques Reis fizeram contribuições que podem ser consultadas no artigo 
Manejo dos Pais Frente à Expressão de Raiva dos Filhos. As autoras tiveram por objetivo verificar o manejo parental diante à expressão da emoção de raiva dos filhos.

Propriedades Psicométricas da Escala de Intenções Frente à Infidelidade (EII) é de autoria de Valdiney Veloso Gouveia, Renan Pereira Nascimento, Bruna da Silva Nascimento, Tátila Rayane de Sampaio Brito, Alessandro Teixeira Rezende e Maria Gabriela Costa Ribeiro. Os autores objetivaram adaptar para o contexto brasileiro e conhecer os parâmetros psicométricos da Escala de Intenções frente à Infidelidade.

No estudo Psicologia escolar e relação família-escola: um levantamento da literatura foi realizado um levantamento da literatura à respeito de intervenções na área da psicologia escolar direcionadas à relação família-escola em bases de dados científicas. O trabalho é de autoria de Jéssica Andrade de Albuquerque e Fabíola de Sousa Braz-Aquino.

Jaqueline de Carvalho Rodrigues, Juliana de Lima Müller, Maria Alice de Mattos Pimenta Parente, Cristiano Esteves, Rochele Paz Fonseca e Jerusa Fumagalli de Salles realizaram a pesquisa intitulada Efeito de idade e escolaridade no Instrumento de Avaliação Neuropsicológica Breve NEUPSILIN. Os autores objetivaram compreender os efeitos da escolaridade e faixa etária e suas interações no desempenho de adultos no Instrumento de Avaliação Neuropsicológica Breve NEUPSILIN.

Recidiva oncológica: olhares dos profissionais hospitalares sobre as dificuldades do paciente pediatrico teve por intuito conhecer as percepções de profissionais de oncologia acerca das dificuldades de crianças e adolescentes em relação à recidiva de cancer. A autoria é de Susana Caires, Marta Machado, Maria Conceição Antunes e Ana Sofia Marques Melo.
Antonio Paulo Angélico, Murilo Freitas Bauth e Arthur Keller Andrade realizaram a pesquisa Estudo Experimental do Falar em Público Com e Sem Plateia em Universitários. O objetivo dos autores foi comparar a frequência dos marcadores comportamentais de ansiedade entre grupos com e sem plateia, frente à situação experimental do falar em público.

Ao final dessa edição é apresentado o trabalho de Ilana Andretta, Jéssica Limberger, Jaluza Aimèe Schneider E Luana Thereza Nesi de Mello, Sintomas de Depressão e Ansiedade em Usuários de Drogas em Tratamento. Os autores investigaram os níveis de estresse, ansiedade e depressão em homens e mulheres em tratamento em Comunidades Terapêuticas, além de relacionar tais níveis ao tipo de substância utilizada e características sociodemográficas.

\section{Referências}

Barata, G. (2015). Em revisão: o impacto da produção científica brasileira para o Brasil. Ciência e Cultura, 67(4), 06-08.

Guedes, M.C. (2011). Equívocos na publicação científica: algumas considerações. Psicologia USP, 22(2), 387-398.

Trzesniak, P. (2009): A estrutura editorial de um periódico científico. In: A. A. Z. P. Sabadini, M. I. C. Sampaio, \& S. H. Koller (Orgs.), Publicar em psicologia: um enfoque para a revista científica (pp. 87-102). São Paulo: Associação Brasileira de Editores Científicos de Psicologia; Instituto de Psicologia da Universidade de São Paulo. 